\title{
Power and powerlessness
}

\section{John Launer}

Many years ago, I came up with an idea that medical students should each have to sign a special consent form when they started their training. The form would allow their medical school, at some random moment in the next few years, to admit them to hospital with an imaginary illness. According to this scheme, every student would suddenly receive a message out of the blue, saying that they had contracted severe pneumonia, a compound fracture of the leg or some other major condition. They would then be admitted to hospital and given more or less exactly the same treatment as if their assigned problems were genuine. Some might be put on intravenous drips and gastro-nasal feeds. Others might have limbs put in plaster casts and on traction. All of them would be confined to bed.

For some students, discharge after a week or two might be followed by having to move around on crutches or in a wheelchair for a further length of time, or even for the rest of their course. One or two might be obliged to simulate even worse disabilities-for example, being blindfolded for several weeks in order to experience the effects of a sudden loss of sight. There would be no appeal against these arrangements on the grounds that they were about to take their exams, go on holiday, or get married, or for any personal reasons. Just as in real life, they would have to accept the condition that had struck them down, and adjust to it.

My proposed scheme was of course entirely impractical, not to mention cruel and unethical. For that reason, I don't think I even mentioned it to anyone else at the time. However, its rationale was completely serious. It was to give all future doctors, at an early stage in their training, a realistic experience of what illness and hospital admission are actually like. They would learn how frustrating it can be to have one's life suddenly and catastrophically disrupted, and what it is like to be completely fit at one moment and then handicapped the next. It might teach them something else as well: how powerless patients can feel, not just

Correspondence to: Dr John Launer, London Department of Postgraduate Medical Education, Stewart House, 32 Russell Square, London WC1B 5DN, UK; jlauner@londondeanery.ac.uk because of their illnesses but because of what happens to them once they fall into the hands of the medical profession.

\section{TRAUMATIC DISRUPTION}

For hospital staff, admissions are just routine events, scarcely more dramatic than customers arriving in a shoe shop to buy a pair of shoes. For patients, by contrast, it represents a threefold loss of power. Firstly there are the bodily symptoms themselves - the pain, breathlessness, immobility or whatever else brought you into hospital. Then there is the traumatic disruption of your normal life, with all its comforting regularity and its assumed sense of control. But in addition there is a loss of power relative to the people who are looking after you, and to doctors in particular. For some patients, this aspect of their powerlessness is the worst.

As any patient will tell you, the power differential is not just about doctors being well and patients being ill, or even about doctors being in the hospital voluntarily while patients are there on the whole without much choice. It is about the enormous range of privileges that any doctor-even the most junior-possesses by comparison with a person lying in a hospital bed. These include the privileges of standing up while the patient lies down, and of being dressed in normal clothes while the patient is in pyjamas. They include the rights of deciding if and when to come and talk to the patient, how much time to spend in doing so, and what to tell or not to tell. Each one of the unthinking everyday rituals of ward life carries with it a set of choices that are available to the doctor, while the patient can influence them little or not at all.

There is another more pervasive aspect of doctors' power, although from inside the medical profession we may have little awareness of it. The French historian and philosopher, Michel Foucault, called it "the medical gaze". He used the term to describe the way we look at other people not as fellow humans, with subjective feelings and needs as rich as our own, but as objects of detached curiosity. $\mathrm{He}$ considered that this attitude wasn't an expression of scientific advance as we might believe. Instead, he regarded it as a distinctly political state of mind, linked to wider forms of oppression including economic and judicial ones.

When doctors examine the surface of the body for evidence of disease, or poke into orifices to explore its interior, our overall purpose, according to Foucault, is to demonstrate and enact a particular kind of power. The way we do this, he argued, is an exact parallel to the way that the police, the tax authorities or other agents of the state exert power in their own different ways as well. Most doctors would probably find Foucault's thinking in this respect excessively harsh and one-sided. Perhaps it is, but it could account for much of the fear and alienation that patients feel when they come into contact with us. It could also help us to make sense of oppressive behaviour on the part of doctors, including widespread incivility, or the stigmatisation of certain patients including those on the social margins.

\section{SHARING POWER}

Arbitrary and compulsory admission to hospital is unlikely to find a place on the medical school curriculum, and nor is Michel Foucault. However, there is a great deal we could do to sensitise ourselves, our students and our trainees, to issues of power and powerlessness in medicine. When we take histories, we could inquire about the trauma of admission as well as its cause. We could ask not just "where did the pain start?" and "what were you doing at the time?", but also "what were you planning to do?" and "what is going to happen now that you can't?" We could consider how our daily ceremonies-our ward rounds or outpatient clinics-can distance and humiliate patients in a hundred different ways instead of engaging them as equal partners. We could learn to use our speech and body language in ways that expressed a willingness to share power rather than imposing it.

As doctors, most of us probably don't think about our power as much as we should. Like people in any other job, we are preoccupied for much of the time by the constraints of our work: annoying regulations, irritating colleagues or managers, and shortages of time, money and other resources. Yet power over patients is constantly present in all our work. How we use or abuse it can make as much difference to them as the quality of our technical care.

\section{Competing interests: None declared.}

Postgrad Med J 2009;85:280.

doi:10.1136/pgmj.2009.081885 